\title{
Inovações no Ensino Médico e Outras Mu- danças: Aspectos Históricos e na Faculdade de Medicina de Ribeirão Preto-USP
}

\author{
Maria de Lourdes Veronese Rodrigues \\ Docente. Membro Suplente da Comissão de Cultura e Extensão Universitária. Membro da \\ Comissão de Publicação da Revista Medicina e Coordenadora desta Edição Especial
}

$\mathrm{O}$ primeiros alunos de Medicina da Hisória, em pequeno número (às vezes um por médico), recebiam ensino preceptoral, acompanhando seus mestres no atendimento de pacientes. Esses mestres estavam cientes dos conhecimentos prévios de seus alunos e de suas necessidades. Poder-se-ia dizer que o processo de ensino/aprendizado era "centrado na resolução de problemas e no aluno".

À medida que a demanda foi aumentando, foram organizadas as primeiras escolas médicas, sendo o ensino estruturado em poucas unidades, com "aprendizado integrado", havendo preleções formais para todo o grupo, mas, ainda, com priorização das atividades em pequenos grupos.

No decorrer dos séculos, o Ensino Médico passou por épocas em que eram valorizadas aulas teóricas, com o ensino "centrado no tópico de conteúdo e no professor", seguidas de épocas em que voltava a valorização do ensino preceptoral, sucedendo-se os modelos que, geralmente, eram ditados pelas escolas mais proeminentes no momento. Essas escolas, até o século XIX, foram predominantemente européias. Na maioria das vezes, as mudanças não levavam em consideração as necessidades da sociedade nem as aspirações dos alunos. No que diz respeito ao conteúdo, foram sendo introduzidas inovações decorrentes das mudanças na profissão médica, que foram mais notórias depois da "Revolução Industrial".
O ensino médico, em outros países da América Latina, iniciou com base nas estruturas vigentes na Península Ibérica, mas as primeiras escolas médicas brasileiras seguiram os "modelos francês e alemão", uma vez que, apesar das idéias inovadores de D. João VI, Portugal não apoiava o ensino de Medicina em suas colônias. Também era na França e na Alemanha que os professores de Medicina faziam seus estágios de aperfeiçoamento/especialização. Os aparelhos e instrumentos eram adquiridos com a ajuda de fundações estrangeiras, pois nossas primeiras instituições de apoio à pesquisa e ao desenvolvimento tecnológico foram criadas na metade do século XX.

No final do século XIX, escolas médicas dos Estados Unidos da América (a maioria das quais seguia a "escola inglesa"), organizadas na Association of American Medical Colleges e preocupadas com problemas existentes nos cursos que ministravam, iniciaram processo de revisão de seus currículos, o que culminou com o "Relatório Flexner". Passou-se, então, a valorizar modelo que enfatizava a pesquisa, a tecnologia e a superespecialização, assim como a separação do ensino básico do clínico. Esse modelo tornou-se nova referência de excelência de Ensino Médico e, ao redor do mundo, diversas escolas o adotaram; no entanto, muitas delas não acompanharam as mudanças que foram sendo introduzidas no "modelo americano", com o passar dos anos. 
Inovações e outras mudanças, que incluem retomada de métodos anteriormente abandonados, continuaram a ser introduzidas na Educação Médica, determinadas principalmente por: avanços da ciência e da tecnologia para diagnóstico e tratamento e industrialização; mudanças de legislações; mudanças econômicas, políticas e sociais, com a conseqüente modificação do sistema de saúde e valorização da prevenção; surgimento de diferentes doenças; descoberta de novos medicamentos; e por pressões dos alunos e pela vontade de reitores, de diretores, de departamentos de ensino e de colegiados. Deve ser lembrado que os "fatores humanos" geradores de mudança também são fontes de resistência a mudanças.

Entre essas inovações, muitas das quais datam das últimas décadas do século XX, podemos destacar: integração docente-assistencial; criação do Internato e da Residência Médica; aumento da responsabilidade dos alunos; aprendizado centrado em problemas; atividades de tutoria; estímulo ao desenvolvimento de raciocínio crítico; técnicas de avaliação (auto-avaliação, avaliação por pares, exames objetivamente estruturados, provas nacionais - que podem avaliar também as escolas médicas); diferentes formas de ingresso; criação de disciplinas eletivas; tempo livre para estudo e aquisição de cultura geral; estímulo à educação médica continuada e desenvolvimento de habilidades que permitam ao egresso o gerenciamento dela ao longo da vida; formação e reciclagem dos docentes; informatização e comunicação; Medicina baseada em evidências; Medicina de família; disponibilização de material didático local; experiência clínica precoce; integração de temas básicos com clínicos; multi-disciplinaridade; ênfase na prevenção; ensino na comunidade (extramuros); uso de pacientes padronizados e de manequins e criação de centros de educação médica, que visem ao apoio educacional e pedagógico aos alunos e à formação didática e pedagógica dos docentes, que passaram a ter outros papéis além do de "transmissores de conhecimentos".

A metade do século XX foi marcada pelo fim da Segunda Guerra Mundial e início da Guerra Fria, e, no Brasil, também, pela redemocratização. As mudanças sociais aconteciam, já existiam os primeiros institutos de previdência e os trabalhadores começaram a exigir cuidados de saúde diferentes dos que recebiam nas Santas Casas, principal campo de estágio dos estudantes de Medicina. Assim, faziam-se necessárias mudanças nos currículos das escolas médicas brasileiras, estimulando a integração docente-assistencial em todos os níveis de atenção à saúde, o que nem sempre ocorreu. Por outro lado, o Internato formal e a Residência Médica estavam sendo introduzidos no Brasil nessa época, propiciando maior carga horária em atividades de "treinamento em serviço", com benefícios para os pacientes, assim como o acesso destes a serviços especializados.

A mobilização da sociedade brasileira, uma das decorrências da redemocratização, fez com que surgisse a preocupação com a interiorização do Ensino Superior. Isso viabilizaria o acesso de muitos à cultura e a profissões liberais, assim como seria um fator de progresso para cidades distantes da Capital. Projetos elaborados por profissionais e líderes de comunidades tiveram o apoio e a aprovação do Governo e da Universidade, sendo criadas novas Instituições de Ensino Superior, entre as quais a Faculdade de Medicina de Ribeirão Preto (FMRP-USP).

Pretendia-se que a nascente escola médica tivesse características inovadoras em relação a outras escolas nacionais e a sua estruturação levou em consideração o "modelo americano" vigente; assim, ficou decidido valorizar as atividades de pesquisa, a separação do ensino básico do clínico e o tempo integral. E, embora houvesse professores "catedráticos", o ensino era centrado em departamentos, apesar de estes não terem ainda as características atuais, pois elas datam de 1970 e são decorrentes da Reforma Universitária .

Quatro décadas mais tarde, a força dessa estruturação departamental fez-se sentir nas resistências à implantação da nova estrutura curricular (acompanhada de processo padronizado de avaliação dos resultados), com a qual se pretendia centrar o ensino na Comissão de Graduação. A reforma ocorreu, mas não foi completa. Em muitos casos, em vez de integração obteve-se contigüidade de temas relacionados. Como "a resistência a mudanças é inerente ao ser humano", poucos anos atrás, resistiu-se também, bravamente, à reestruturação departamental exigida pela Universidade. Depois de muita argumentação, departamentos foram reestruturados e as exigências foram satisfeitas. Mas, mais uma vez, o processo ocorreu parcialmente. Embora haja resultados muito positivos, perdeu-se a oportunidade de uma integração ampla.

Os primeiros professores catedráticos da FMRP-USP foram recrutados pelo primeiro Diretor, o Prof. Dr. Zeferino Vaz, em centros de excelência da Europa e do Brasil, de onde provieram também os primeiros professores assistentes. Isso fez que o "modelo europeu de Ensino Médico" também tivesse alguma influência na consolidação da FMRP-USP. 
Atualmente, é enfatizado que um professor de Medicina deva ser mais do que um "conferencista", sendo valorizados os papéis de: médico/biólogo/psicólogo, etc. com habilidade e competência profissional; provedor de informações em aulas formais e na prática médica; tutor/facilitador, sendo o aluno o gerenciador do aprendizado; gerador de conhecimentos (pesquisador); produtor de material didático; planejador de cursos/currículos; modelo de atitudes e valores; avaliador de alunos e institucional; membro ativo da comunidade universitária; administrador e captador de recursos materiais para a Instituição.

Os primeiros docentes da FMRP-USP tinham um perfil semelhante ao do "padrão ouro" de docente atual. É verdade que eles não eram tutores/facilitadores e nem permitiam que o aluno gerenciasse o aprendizado, mas essa inovação foi introduzida no Ensino Médico quase duas décadas mais tarde, quando Harold Barrows estruturou a Faculty of Health Sciences Mc Master University com base no "aprendizado centrado em problemas". Os antigos professores não só planejavam o currículo, como também estipulavam os objetivos das unidades de ensino, sem interferências, uma vez que os objetivos terminais da Faculdade de Medicina de Ribeirão Preto, só foram formalizados pela Congregação em 1987.

Como foi mencionado, a inovação "professor como gerador e não só como transmissor de conhecimentos", foi introduzida já no projeto da FMRPUSP; os primeiros docentes eram médicos de reconhecida competência profissional e a maior parte deles tinha grande cultura geral; muitos ministravam aulas práticas; colaboravam na administração da escola; captavam recursos de fundações estrangeiras para equipar seus laboratórios e clínicas, assim como para realizar suas viagens de estudos; serviam como modelos de atitudes e valores para seus alunos; funcionavam como avaliadores; e alguns deles eram excelentes ministradores de aulas teóricas.

São, também, exemplos da visão ampla de nossos pioneiros a implantação do ensino extramuros (Cássia dos Coqueiros) por Pedreira de Freitas; o "Curso Conjunto", exemplo de ensino integrado, coordenado por Hélio Lourenço de Oliveira e Rui Escorel Ferreira Santos; e as "excursões" que Almiro Azeredo (que aliás é também um conferencista brilhante) fazia com os alunos de graduação a escolas da periferia e a Cassia dos Coqueiros, para que eles aferissem a acuidade visual e praticassem o exame ocular externo, exemplo de integração docente-assistencial. Além disso, enquanto, no final do mês de agosto de 2002, nos anfiteatros e jardins do Campus da Universidade de Lisboa, a Association for Medical Education in Europe (AMEE) comemorava os 30 anos da introdução do OSCE (Objective Structured Clinical Evaluation), por Ronald Harden, em nossos anfiteatros e jardins prosseguiam as comemorações dos 50 anos da Faculdade de Medicina de Ribeirão Preto e, consequientemente, os quase 50 anos das famosas "gincanas" da Anatomia que, embora não aplicadas na avaliação de competências clínicas, eram avaliações objetivamente estruturadas por estações.

Os docentes atuais continuam entendendo a multiplicidade dos papéis do professor de Medicina, uma vez que, em inquérito realizado recentemente, mais da metade dos componentes da população amostral valorizou, além da capacidade de transmitir conhecimentos teóricos, a capacitação profissional, a geração de conhecimentos, a ministração de aulas práticas, a importância de planejar o ensino e de realizar avaliações adequadas e a capacidade de exercer o papel de tutor/facilitador.

Quando pressões da sociedade fizeram com que a Universidade Pública estudasse a implantação de novas vagas, a FMRP-USP, conduzida pelo seu atual Diretor, criou 4 novos cursos ( 2 dos quais, Fisioterapia e Terapia Ocupacional, já estão implantados) e compartilhou a criação de mais um, em parceria com a Faculdade de Filosofia, Ciências e Letras. Apesar de esses cursos propiciarem a contratação de novos docentes, vários dos atuais professores estão em processo de adaptação a esse novo desafio - participar da formação de profissionais com perfil diferente daquele do médico.

Embora nunca tenha sido possível o acesso de todos os docentes a programas ou cursos formais na área de Ensino, ao longo dessas 5 décadas, a FMRPUSP investiu na formação didática e pedagógica de seus docentes. Sempre que houve interesse individual ou de pequenos grupos, a Instituição e a Universidade (com a ajuda de entidades financiadoras de pesquisa e projetos, nacionais ou internacionais) propiciaram a participação em cursos, workshops, seminários, congressos e a realização de visitas a escolas médicas, consideradas "inovadoras". Resultado desse investimento institucional é a possibilidade de que algumas disciplinas de pós-graduação relacionadas à Didática e à Pedagogia Médica sejam ministradas por docentes da FMRP-USP, sem auxílio externo. Como outros exemplos, podemos citar as mudanças nos métodos de 
avaliação, que estão sendo introduzidas em unidades de ensino específicas, e a avaliação terminal - com métodos de comprovadas validade e fidedignidade das duas estruturas curriculares (antiga e nova), através do desempenho dos egressos. Além disso, desenvolve-se na FMRP-USP, pesquisa em Ensino Médico, de nível internacional.

Na FMRP-USP, não há um Departamento ou Centro de Ensino Médico. Mas, já no final da década de 80 começou a ser estruturado o Núcleo de Apoio Psicopedagógico (NAPP), implantado em 1990, depois transformado em Centro de Apoio Educacional e Psicológico (CAEP), que está envolvido com diversos projetos institucionais, assessora a Comissão de Graduação, mas está ainda mais voltado para o apoio aos alunos.

Ainda no que diz respeito aos alunos, a FMRPUSP aderiu ao Programa Especial de Treinamento (PET), da CAPES, propiciando a alguns a oportunidade de maior contato com atividades de ensino, de pesquisa, assim como culturais e de extensão.

Na década de 80 ocorreram, por iniciativa da então Comissão Coordenadora de Ensino e da Congregação, vários movimentos (ex: seminários) de avaliação do ensino ministrado na FMRP-USP, sendo verificada a necessidade de reforma curricular.

Além disso, no final daquela década, o então Diretor, Prof. Dr. Dalmo de Souza Amorim, coordenou processo de análise da instituição como um todo, seguida de planejamento, com a participação de muitos, e elaboração de "Plano Diretor", onde também estava contemplada a reforma curricular.

Sempre atenta as inovações do Ensino Médico, a FMRP chegou a considerar o Aprendizado Centrado em Problemas, como modelo de estrutura curricular. Mas, levando em conta as características da Instituição e de seus alunos, decidiu não implanta-lo, ficando aberta a possibilidade de sua utilização como técnica de ensino em segmentos específicos do curso médico.

A proposta aprovada de reestruturação curricular da FMRP contemplava a incorporação das 20 vagas do extinto Curso de Ciências Biológicas; permitia a flexibilização curricular, voltando a escola a oferecer 2 titulações; propunha a integração parcial de conteúdos, possibilitando a organização por sistemas; pretendia a ampliação do Internato; e valorizava as atividades de atenção primária.

Além do Departamento de Medicina Social, responsável, também, pelo gerenciamento do Centro de Saúde-Escola, alguns outros departamentos praticavam o ensino extramuros há algumas décadas. Essas atividades, embora ainda insuficientes para uma escola médica moderna, tinham sido ampliadas, principalmente depois da Assembléia Nacional Constituinte de 1988 e da conseqüente reforma do Sistema Nacional de Saúde do Brasil, que resultou na implantação do Sistema Único de Saúde (SUS), descentralizado, hierarquizado e valorizando a atenção à saúde da família. Com a nova estrutura curricular, as atividades de integração docente-assistencial foram, mais uma vez, ampliadas. Na época, também começava o envolvimento da FMRP-USP na capacitação de recursos humanos para a saúde da família. Apesar de não haver uma disciplina específica relacionada à Medicina de Família, na nova estrutura curricular surgiram os "Estágios Integrados" e há Residência Médica em Medicina de Família, gerenciada pelo Departamento de Medicina Social. Assim, foram quebradas mais algumas barreiras ao acesso aos cuidados médicos, com a contribuição de nossa escola.

A hierarquização do sistema de saúde, assim como das novas solicitações do "paciente-cidadão", requereram mudanças, também no Hospital das Clínicas (destinado predominantemente aos níveis terciário e quaternário), na Unidade de Emergência e nas outras unidades de apoio. Está sendo altamente benéfica a humanização do atendimento no Hospital das Clínicas e na Unidade de Emergência, que, ao lado das atividades comunitárias, das "ligas" do Centro Acadêmico, dos grupos de apoio aos pacientes, e do ensino do "suporte à vida" do paciente traumatizado, estão tendo influência positiva na formação global dos alunos da FMRP-USP.

Ocorreram, também, mudanças no ensino ministrado pela FMRP-USP decorrentes dos avanços da ciência e da tecnologia, do surgimento de novas doenças (principalmente a Síndrome da Imunodeficiência Adquirida - aids) e de novos medicamentos, assim como do estímulo a atividades humanísticas, um dos objetivos da nova estrutura curricular.

Como mencionado anteriormente, houve resistências à reforma curricular, que impediram que ela fosse mais ampla. Há aspectos negativos e não houve alteração significativa na consecução dos objetivos educacionais da Instituição. Mas há, também, resultados positivos e foi objetivamente mensurado, no processo de avaliação que acompanhou essa reforma, que houve "aumento da aquisição de conhecimentos nas áreas mais gerais da atuação médica e melhora significativa do desempenho prático em habilidades clínicas fundamentais e, sobretudo, nas habilidades psicomotoras envolvidas na realização de procedimen- 
tos", talvez pelo aumento das atividades de atenção primária e pela duplicação do tempo destinado ao Internato.

Embora, desde o início da década de 70, pela sua posição de destaque como centro de ensino e pesquisa, a FMRP-USP tivesse implantado seu Curso de Pós-Graduação; a pesquisa estivesse presente na Instituição desde a fundação, existindo excelentes laboratórios; a oportunidade de iniciação científica estivesse bem consolidada e a produção científica, incluindo, também, pesquisa clínica e na comunidade, se tornasse cada vez mais destacada, somente na década de 90 foi formalizada a Comissão de Pesquisa, com novos benefícios para a Instituição.

Da mesma forma, a Cultura e as Atividades de Extensão, também existentes desde o início, e, a partir da década de 80 conduzidas pela Assessoria Cultural, passaram a ser gerenciadas pela Comissão de Cultura e Extensão Universitária, com amplo campo de atuação.

Na última década, a FMRP-USP investiu também em Informática e Comunicação, melhorando as atividades-meio e as atividades-fim, enriquecendo a Documentação Científica e possibilitando a preparação para o início de atividades de "Educação à Distância", e investiu em órgãos de apoio e laboratórios
(Centro de Medicina Legal, Centro de Química das Proteínas, etc).

Outra proposta do Plano Diretor era a modificação da estrutura administrativa, embrião da estrutura atual das atividades-meio, que atualmente são exercidas de maneira integrada, mas compartimentalizada.

Recentemente, acompanhando as tendências atuais de gerenciamento de instituições, criou-se o "Programa de Gestão da Qualidade da FMRP-USP," que conta com a parceria da Escola Politécnica-USP e está apresentando resultados muito positivos.

Paralelamente, vários serviços do Hospital das Clínicas, da Unidade de Emergência, do Hemocentro, de laboratórios, tornaram-se Centros de Referência e o crescimento da Fundação de Apoio ao Ensino e à Pesquisa (FAEPA), propiciou recursos que colaboraram para o engrandecimento da Instituição.

Assim, a FMRP-USP vem aderindo à importantes tendências do Ensino de Ciências da Saúde; está investindo cada vez mais na adequação de seus egressos à necessidades atuais do país e chegou aos 50 anos em processo contínuo de adaptação ao "padrão ouro" de ensino, pesquisa e extensão de serviços à comunidade.

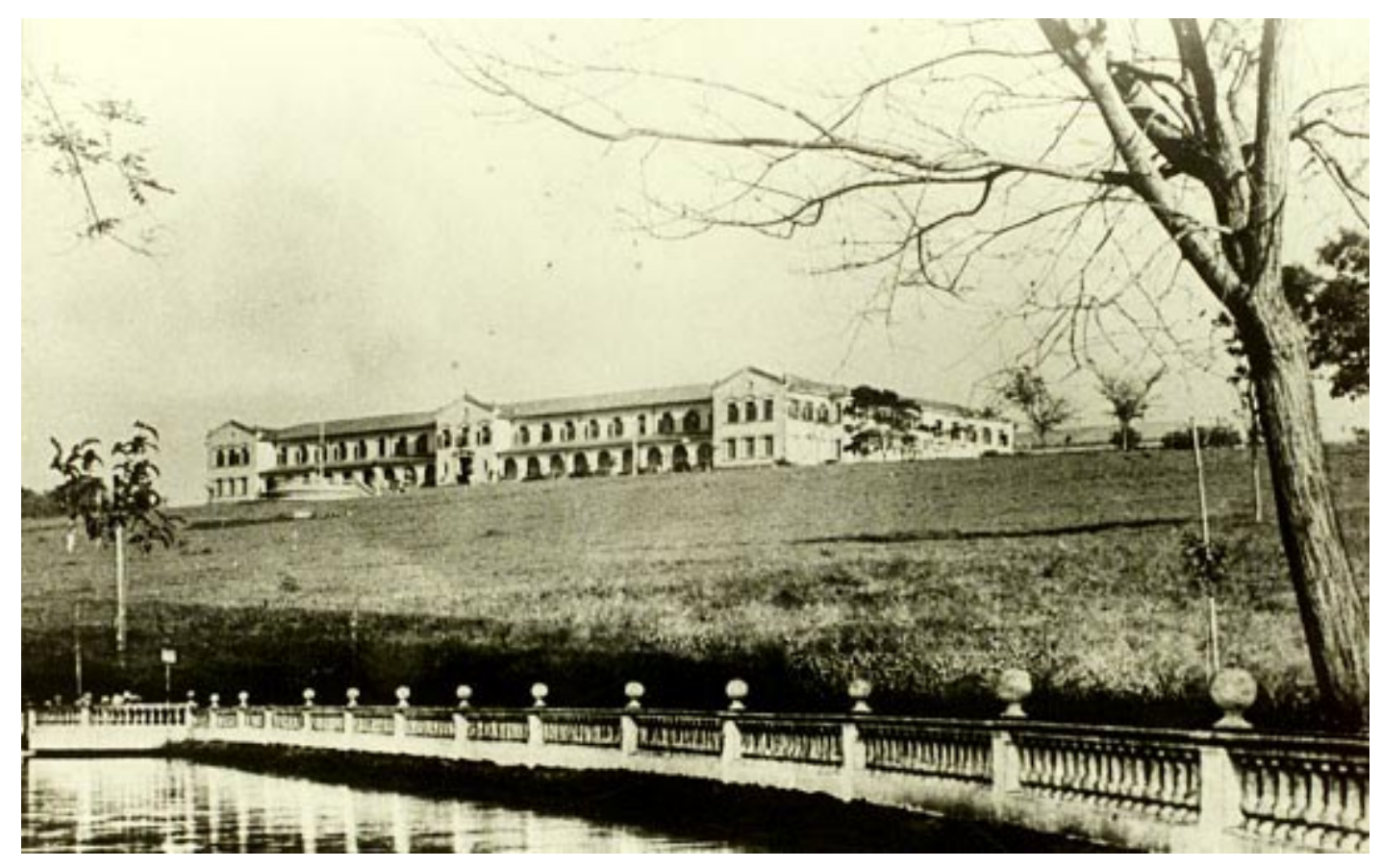

FMRP-USP, vista do prédio central. 